\title{
Derechos humanos y migraciones: un análisis de la realidad Española
}

\author{
Human rights and migration: an analyse of the Spanish reality
}

Edileny Tomé da Mata ${ }^{1}$

\begin{abstract}
Resumen
Desde un punto de vista complementario y atrevido este manuscrito plantea la toma en consideración de la condición sociojurídica de los inmigrantes como uno de los factores en el acceso y disfrute de los derechos humanos por parte de los migrantes residentes en España y de forma introductoria en Brasil. Para ello, primero realiza una aclaración en torno a tres conceptos clave en la materia tales como Derechos Humanos, migración y condición sociojurídica; segundo hace una somera reflexión sobre la ciudadanía migratoria y finaliza mostrando, a través de preceptos de la Ley Orgánica de Extranjería, así como de la Constitución Federal brasileña, la prevalencia de la condición sociojurídica y nacionalidad de los migrantes, sobre las condiciones humana, sociopolítica y familiar de los migrantes.
\end{abstract}

Palabras clave: Derechos humanos, migrante, condición sociojuríca

\begin{abstract}
From a complementary and daring point of view, this text raises the consideration of migrants' social and legal condition as one of the factors in the access and enjoyment of rights on the part of migrants' residents in Spain and in Brazil as an introductory point of view. For that, first makes an explanation on three key concepts in the subject as Human Rights, migration and social and legal condition; second, makes a brief reflection about migratory citizenship and finish by showing, from the precepts of the Spanish Foreign Organic Law, and Federal Brazilian Constitution, the prevalence of migrant social and legal condition as well as their nationality, over human, social and political, and familiar migrants' conditions.
\end{abstract}

Keywords: Human rights, migrant and socio legal condition

\section{Introducción}

La cuestión sobre los sistemas de garantía de derecho ya ha sido disertada por varios autores e intelectuales en varias ocasiones apuntando temas a la vez divergentes y complementarios. Así, Barba (1980) y De Luque (1981) pusieron el acento en garantías constitucionales, Ferrajoli, uno de los juristas y filósofos del derecho más respetados y referente de nuestra época, ha desarrollado argumentos en torno a garantías normativas (2004

\footnotetext{
${ }^{1}$ Doctor europeu por la Universidad Pablo de Olavide (Sevilha - España) e investigador post doc CAPES/ PNPD en Unibrasil/ Centro Universitário (Curitiba - Brasil). E-mail: edtomata@gmail.com
} 
(4 ed.)), garantías penales (1995) y democracia constitucional (2011). Por último y sin ánimo de agotar el elenco de juristas garantistas, Pisarello (2007), Courtis y Abramovich (1997, 2002) han desarrollado sus tesis sobre la garantía del derecho en torno a la justiciabilidad de los derechos económicos, sociales y culturales (DESC).

Nuestro interés en este manuscrito es seguir en la senda de los debates planteados en torno a los sistemas de garantía de derecho e introducir, desde un punto de vista complementario y modesto, la condición sociojurídica de los inmigrantes residentes en España como uno de los factores clave en y para el ejercicio de sus derechos tanto fundamentales como básicos. Por condición sociojurídica entendemos la condición de extranjero, trabajador e individuo culturalmente distinto del supuesto marco cultural homogéneo en España.

Pero antes de entrar en materia permitidnos realizar una aclaración sobre los conceptos que creemos relevantes en el presente texto: Derechos Humanos, migrante y condición sociojurídica.

En primer lugar, a diferencia de la concepción convencional o tradicional de los derechos humanos, como simples normas o cuestiones inherentes a la condición humana (BOBBIO, 1991) y por ende metafísicas, entendemos los derechos humanos como productos culturales (HERRERA FLORES, 2005). Es decir, primero se contempla su contextualización, enmarcados en un ámbito socioeconómico, sociocultural y sociopolítico determinado, y segundo, se concibe a los derechos humanos como un proceso de lucha que conlleve al disfrute de condiciones materiales e inmateriales propios de la dignidad humana. Es decir, la necesaria existencia de condiciones que permitan una real actitud y aptitud de los individuos o grupos poblacionales en un ámbito social determinado (HERRERA FLORES, 2008).

En relación con el tema del manuscrito en cuestión es necesario, ante todo, contextualizar los ámbitos socioeconómico, sociocultural y sociopolítico tanto de los grupos poblacionales migrantes, así como de los ámbitos territoriales donde residen. Ello es importante ya que creemos que sin la contextualización caeríamos en las falacias universalistas, metafísicas y vacías de contenidos y concreciones. En el presente artículo tratamos de exponer por un lado cuestiones relacionadas con los grupos poblacionales migrantes en general ya que creemos que, a pesar de sus amplias diferencias, en lo referente a la condición jurídica son comunes, sobre todo en relación a aquellos portadores de una autorización de trabajo y residencia temporales. En cuanto al contexto, teniendo en cuenta que las competencias en materia de nacionalidad, inmigración, emigración, extranjería y derecho 
de asilo siguen siendo de ámbito nacional en España (arts. 149.1.2 y 13 de la Constitución Española - CE) salvo excepciones tras la reforma de la Ley Orgánica de Extranjería (LOEx) del año 2009, hemos preferido contemplar el territorio nacional, eso es el ámbito territorial español.

En segundo lugar, concibiendo a priori la idea de Estado moderno como algo imaginadamente construido (ANDERSON, 2000) y, por ende, igualmente imaginados sus fronteras e identidades apriorísticas, defendemos el desplazamiento de un individuo o grupo poblacional más bien de un lugar a otro (migración) que de un país a otro (inmigración). En este sentido, compartimos a medias los argumentos de las instituciones gubernamentales españolas competentes que razonan y legitiman sus políticas migratorias, entre otros, en base a su legitimidad territorial como Estado, por un lado y, por otro, colaboramos en el fomento del uso de la expresión migración que a su vez sirva de catalizador en la defensa de libertad de movimiento de personas. En esta línea consideramos migrantes a las personas extranjeras residentes y no inmigrantes.

En tercer y último lugar, en el lenguaje académico contemporáneo ya se ha disertado sobre la condición humana (ARENDT, 2003), la condición postcolonial (MEZZADRA, 2008), la condición social, entre otras. Pretendiendo ser defensores del concepto del derecho como experiencia jurídica (TREVES, 1947) y no simplemente desde el matiz positivista, creemos igualmente en la condición sociojurídica. Esta última trataría de visibilizar la influencia de lo jurídico en la condición social, económica, cultural...de un individuo o grupo poblacional determinado. En este manuscrito intentamos, pues, hacer evidente las influencias de la condición jurídica de los grupos poblacionales migrantes en sus respectivas condiciones humana, económica, familiar, entre otras. Es decir, creemos que es tal la prevalencia del ser jurídico del migrante en la sociedad española que invisibiliza otras cuestiones como que es un Ser Humano que necesita medios económicos para sobrevivir, cuenta con una familia, es un ser cultural y con una o varias identidades, cuestiones todas ellas que creemos importantes a fin de complejizar la condición de los grupos poblacionales migrantes y evitar así el simplismo. Este trabajo es el inicio de la investigación en la materia, pues en esta fase resaltaremos los aspectos normativos en materia de extranjería en España que hacen que prevalezca la condición sociojurídica sobre otras antes mencionadas.

Nuestro método de análisis basado en la recopilación bibliográfica sobre inmigración, ciudadanía y derechos humanos tiene como guía por un lado, una realidad compleja en la juegan un papel importante las relaciones de poder y los sistemas de valores que se 
desarrollan en los ámbitos socioeconómicos, sociopolíticos, socioculturales... (HERRERA FLORES, 2008: 80) y, por otro, el que migración es concebida como un proceso desestabilizador de bases conceptuales tradicionales de la sociedad occidental (MEZZADRA, 2011).

En este sentido, hemos dividido el texto en dos partes: primero realizamos una exposición en torno a la ciudadanía y los derechos humanos y, en segundo lugar, exponemos hechos normativos españoles y brasileños que muestran la prevalencia de la condición sociojurídica del migrante sobre las condiciones humana, familiar y social.

\section{Sobre los derechos humanos y la ciudadanía}

\section{Debate en torno a la ciudadanía migratoria}

El concepto de ciudadanía que utilizamos hoy día es fruto de un proceso de construcción que en Europa inició en la Grecia Antigua. Como señala De Lucas y otros autores (2008), desde los inicios ya tenía aspectos excluyentes. Es evidente que desde aquellas épocas no solamente ha cambiado las estructuras políticas, económicas, demográficas, entre otras de la sociedad europea, sino igualmente los marcos de referencia de quién es ciudadano y quién no (MEZZADRA, 2008). Sin embargo, un aspecto de gran relevancia que pervive desde la época decimonónica hasta nuestros días relacionado con la ciudadanía, es su vínculo con la nacionalidad, es decir, la relación entre ciudadanía y Estado-nación (ARANGO, 2006; DE LUCAS, 2006, 2014). En este sentido, la ciudadanía opera en un mundo moderno como una suerte de estatus medieval [...], ligado al nacimiento y protegido por las prerrogativas del Estado, que decide quién será admitido como inmigrante y que impone la naturalización como prerrequisito de adquisición de membresía, excluyendo de la ciudadanía plena a una serie de estatus intermedios ligados a la condición de migrante (VV.AA, 2008). Así, todos aquellos que supuestamente no estén vinculados a un territorio determinado o serán banidos de la membresía.

Esta concepción del vínculo entre ciudadanía y Estado-nación no es una casualidad, sino que se debe especialmente a la fabricación de una identidad nacional homogénea e imaginada (ANDERSON, 2000) a través de creación de narrativas político-fundacionales, la promoción (o imposición) de un idioma común y el fomento del sentimiento de pertenencia y 
de lealtad junto a determinadas instituciones, tradiciones y prácticas (VV.AA., op. cit.). Es lo que Bhabba (1994) denominó la conformación de narrativas donde los jirones, remiendos y harapos de la vida cotidiana [...] deben ser repetidamente convertidos en signos de una cultura nacional coherente, en tanto el propio acto de performance narrativa interpola un creciente círculo de sujetos nacionales. El resultado de todo es, entre otros, la desconsideración de la heterogeneidad existente (VV.AA. op. cit), así como la creación y el fomento de extraños y ajenos a esa cultura homogénea.

A ello se añade que, dada las características de las políticas migratorias europeas, españolas, así como las brasileñas (utilitarista, instrumental, funcional) los inmigrantes no forman parte del escenario político ciudadano. Es decir, se requieren mano de obra temporal a los que se les conceden derechos restringidos vinculados a su condición laboral y, en este sentido, se plantea la presencia migrante como algo provisional, parcial y superficial (DE LUCAS, 2001, 2012).

En la línea de lo antes mencionado se dará pues en la sociedad una especie de estratificación cívica (MORRIS, 2002), que reconocerá derechos formales a los inmigrantes teniendo en cuenta su tipo de autorización de residencia (ARANGO, 2006). Así, a los naturalizados (citizens) se les reconocerá plenos derechos en igualdad de condiciones que los españoles; a los llamados denizens se les reconocerán formalmente casi todos los derechos excepto los políticos; a los migrantes con permisos temporales se les reconocerán los derechos limitados y vinculados a su condición de trabajador o trabajadora, aunque dependiendo del país de origen y, por último, a los inmigrantes irregulares se les privará de todo derecho excepto en circunstancias excepcionales y de urgente necesidad.

Sí a ello añadimos cambios en los modos complejos y articulados en la determinación del ciudadano o no ciudadano (MEZZADRA, 2008) y, por consiguiente, que las claves de delimitación de ciudadanía son otras, el debate se complejiza más. Es decir, mientras que en otros tiempos se definía la figura del ciudadano/a en base a la propiedad u otras cuestiones, hoy en día parece que son ciudadanos/as aquellos/as que dispongan de un trabajo formalmente reconocido y, en base a ello, coticen a la seguridad social, permitiéndoles tener acceso a los derechos, los sociales en particular. La centralidad del trabajo en su vínculo con la ciudadanía será, además, el factor que determinará la satisfacción e integración de un individuo o grupo poblacional en un ámbito social determinado. Ello hará que el individuo o el grupo poblacional se encuentren en una continua inclusión y exclusión, mejor dicho, inclusión diferenciada, debido especialmente, a los desajustes económicos y financieros. En 
otras palabras, estar o no (o sentirse o no) integrado en la sociedad dependiendo de que las circunstancias económicas y financieras se lo permitan o no.

En definitiva, que junto al reconocimiento formal y el ejercicio efectivo del estatus de ciudadano hay un amplio trecho de diferencia. El citizens, denizens o inmigrantes con autorización de residencia temporal pueden tener reconocidos formalmente ciertos derechos en tanto ciudadanos, pero si no logran cumplir o mantener con las claves preestablecidas por la centralidad del trabajo, pueden pasar de un día al otro al lado de los incluidos de forma diferencial, que sería lo mismo que excluidos.

En base a lo antes expuesto, en relación a la concreción de la ciudadanía migratoria creemos que no solamente resulta inviable debido a la inestabilidad y precariedad laboral de los y las migrantes, sino debido igualmente al concepto moderno de ciudadanía y a la condición de straniero de los migrantes (TOMÉ DA MATA, 2011: 185-190). Es decir, la determinación histórica y social apriorística de quién es ciudadano y quién no en España y, la construcción apriorística desde los puntos de vista histórico y social de un individuo o grupo poblacional como extraños y ajenos a los aspectos considerados propios de la sociedad española, son cuestiones clave a la hora de plantear el tema de ciudadanía migratoria. En este sentido, los migrantes comunes en España no solamente quedarán exentos de la condición de ciudadanía por los desajustes económicos y financieros al tratarse de grupos sociales con amplias desigualdades económicas y sociales, sino que además no están apriorísticamente en el listado histórico de Españoles ya que han sido previamente concebidos, por lo histórico y lo social, como ajenos y extraños a la cultura Española.

Frente al escenario mencionado en párrafos anteriores, varios autores reivindican una ciudadanía a posteriori en la que más que reconocimiento formal se dote de condiciones materiales e inmateriales necesarias para el acceso a los derechos (ARANGO, 2006), una ciudadanía diferenciada o multicultural que a su vez requeriría amplios cambios de paradigmas políticos y culturales y, por último igualmente cambios de paradigma en materia migratoria percibiendo ésta última como un fenómeno global, complejo e integral (DE LUCAS, 2006, 2014).

En base a lo expuesto en párrafos anteriores creemos que es de especial relevancia la idea del Ser y Estar en un territorio. Es decir, tal como vimos antes la ciudadanía hoy día todavía se encuentra vinculada a un territorio, a una nación y, a su vez las políticas migratorias españolas, europeas y hasta brasileñas generan en los migrantes una idea de temporalidad en el territorio donde residen. Todo ello será consecuencia de que el migrante, aunque estando en 
un territorio determinado no se sienta del lugar, lo que a su vez generará obstáculos en su proceso de inclusión social. El migrante, pues, no se siente del lugar (Ser) dado que tanto en su imaginario como de la mayoría social él es un extraño y, tan solo está (Estar) porque al ser extraño él debe cumplir con los deberes laborales y regresar al lugar donde se encuentra su pertenencia identitaria.

\section{La condición sociojurídica: clave en la determinación de las condiciones humana, sociopolítica y familiar del migrante}

Percibiendo los Derechos Humanos en tanto proceso de lucha que conlleve a la adquisición de condiciones materiales e inmateriales que hagan que la vida sea digna de ser vivida, tomemos en consideración a la condición sociojurídica del inmigrante como una condición inmaterial que obstaculiza este proceso de lucha, es decir, que obstruye el ejercicio de los Derechos Humanos de los migrantes.

Hablar de condición sociojurídica, como dijimos en párrafos anteriores, no nos referimos solamente a la estratificación cívica según Morris, sino igualmente a las situaciones de regularidad e irregularidad administrativa. En verdad el vínculo entre éstas últimas no existe mucha diferencia no solamente debido a los desajustes económicos y financieros que puedan conllevar a la situación de irregularidad administrativa, sino como dijo Solanes (2001, 2010), la irregularidad administrativa no es un fenómeno natural sino una consecuencia de las políticas de acceso implementada por los propios Estados.

La potestad del legislador para legislar en materia de extranjería y así garantizar el orden político y la paz social está amparada en los artículos 10.1 y 13.1 de la Constitución Española. Otra cuestión es, por un lado, que la lucha contra la inmigración irregular constituya un fundamento de garantice el orden político y de la paz social y, por otro, si en el marco de esta potestad legisladora y estatal se tiene en cuenta ciertos principios éticos básicos (CARENS, 2013).

Como complemento a lo antes dicho, argumenta Ágüelo (2011), que cualquier Estado de Derecho receptor de inmigrantes ha de mantener preferentemente el objetivo de canalizar legal y ordenadamente los flujos migratorios en base a la capacidad de acogida y necesidades y/o posibilidades del mercado de trabajo. Pero lo esencial es que estos principios no sean excluyentes, por ello se debe tener en cuenta su demografía, la cooperación internacional, la solidaridad internacional y la cooperación al desarrollo. 
Sin embargo creemos que estos principios tampoco deben girar en torno a los intereses tan sólo estatales lo que conllevaría a que fueran utilitaristas y funcionales (ZINCONE, 1992, 2011), sino que es necesario también tener en cuenta los desajustes estructurales que impulsan la salida de los migrantes de sus respectivos países de origen o residencia, y que ciertos tratos a los migrantes residentes en 'suelo europeo' supone la involución en los principios éticos, culturales, sociales y democráticos de las sociedades europeas (MEZZADRA, 2010).

En el marco de esta potestad antes mencionada, entre otras cuestiones, se deja bien claro que el ejercicio de los derechos por parte de los extranjeros depende de su situación de regularidad o irregularidad administrativa (art. 2 bis e) de la Ley 2/2009).

No es nuestra intención analizar en este apartado todos los derechos de los extranjeros residentes en España, sí verificar el vínculo en el ejercicio de algunos de ellos con la condición sociojurídica por un lado y, por otro, vulneraciones de otros derechos obviando cuestiones básicas como la unidad familiar. Así, en las siguientes líneas trataremos de detallar el ejercicio de ciertos derechos sociales y colectivos y su vínculo con la condición sociojurídica de los inmigrantes. Igualmente haremos una pequeña mención introductoria al concepto de igualdad entre extranjeros y nacionales en Brasil.

\section{Ejercicio de los derechos sociales y colectivos y la condición sociojurídica de los migrantes}

El ejercicio de los derechos sociales y colectivos por parte de los inmigrantes residentes en España generó polémicas cuando de la reforma de la Ley Orgánica 4/2000 por la Ley Orgánica 8/2000 bajo el gobierno del Partido Popular. La reforma en cuestión restringía el ejercicio de los derechos de manifestación, reunión, asociación, sindicación, huelga y educación tan sólo a los inmigrantes en situación de regularidad administrativa. Esto le valió varios recursos de inconstitucionalidad y, por consiguiente, la Sentencia del Tribunal Constitucional (STC) 236/2007.

Hoy día tras la reforma de la Ley Orgánica de Extranjería 2/2009 ha habido varias modificaciones en la normativa acatando así lo establecido en la STC 236/2007 así como varias Directivas europeas en la materia. Sin embargo, el ejercicio de ciertos derechos sigue vinculado a la situación jurídica del migrante.

En la línea de lo mencionado en el párrafo anterior, aunque la STC establezca que el ejercicio del derecho de sindicación y huelga deba realizarse independientemente de la 
condición sociojurídica del migrante, es evidente que para afiliarse a un Sindicato y poder ejercer el derecho de huelga es necesario ser trabajador por cuenta ajena o por cuenta propia provisto de su autorización de trabajo y residencia (MOYA, 2011).

Igualmente se requiere una determinada condición sociojurídica cuando se trate del ejercicio del derecho de participación política. Es decir, a pesar de que el art. 6 de la Ley Orgánica de Extranjería (LOEx) reconozca el ejercicio del derecho de participación pública a los extranjeros, ello se contradice con lo establecido en el art. 13.2 de la Constitución Española (CE) que restringe su ejercicio a los españoles y aquellos países que tengan un Acuerdo de Reciprocidad con el Estado español. En otras palabras, se requiere la condición de naturalizado y/o dependiendo de las relaciones bilaterales entre España y el país de origen del migrante para la efectividad del derecho de participación política.

El acceso a las ayudas públicas en materia de vivienda (art. 13 LOEx) también requiere la situación de regularidad administrativa del migrante. Además, en el contenido del artículo se denota una cierta 'estratificación cívica' entre los migrantes, ya que se establece que los residentes de larga duración tienen derecho a dichas ayudas en las mismas condiciones que los españoles a diferencia de los extranjeros temporales.

El ejercicio del derecho de educación sigue la senda de la STC 236/2007 y reconoce dicho derecho a menores de dieciséis y menores de dieciocho años. El derecho en cuestión incluye el acceso a una educación básica, gratuita y obligatoria y supone la obtención de la titulación académica correspondiente y el acceso al sistema pública de becas y ayudas en las mismas condiciones que los españoles.

El derecho en cuestión también es reconocido a los extranjeros residentes (en situación de regularidad administrativa), pero no a los extranjeros en situación de irregularidad administrativa a los que relega a ‘enseñanzas para su mejor integración’ (art. 9.3 LOEx).

Otra cuestión espinosa en la relación entre el ejercicio de los derechos y la condición sociojurídica de los migrantes es la reagrupación familiar. Su ejercicio no solamente requiere la regularidad administrativa a la hora de tramitar la documentación de reagrupación familiar y otros requisitos más (art. 18 LOEx), sino que además para la reagrupación de ascendientes menores de 65 años se requiere la justificación de razones humanitarias, y para ascendientes mayores de 65 años tan sólo podrá realizarla aquellos extranjeros que tengan la residencia de larga duración, tarjeta azul o se encuentren el régimen especial de investigadores.

El derecho en cuestión no se reconoce como un derecho fundamental a pesar de que el art. 8 del Convenio Europeo de los Derechos Humanos lo reconozca como tal (MOYA, 2011). 
Otro obstáculo en las condiciones para un ejercicio efectivo de este derecho es la no firma y ratificación por parte de España, ni de ningún Estado europeo, ni del Estado brasileño de la Convención Internacional para la protección de los trabajadores extranjeros y sus familias, de la ONU de 1990, donde se establece varios preceptos de protección de los trabajadores migrantes y sus familias. A fin de profundizar en la relación entre la Convención antes mencionada y la LOEx, así como la necesidad de que el Estado español ratifique dicha Convención vid. "De Lucas; Ramón y Solanes. Informe sobre la necesidad y oportunidad de ratificación por España de la Convención internacional de la Organización de las Naciones Unidas de 1990 sobre la protección de los derechos de todos los trabajadores migratorios. 2009"

Siguiendo en la relación entre el ejercicio de los derechos y la condición sociojurídica de los migrantes, es igual de controvertido el ejercicio de los derechos sociales (art. 14 LOEx). El acceso a los servicios y prestaciones sociales básicas está permitido independientemente de la situación jurídica del migrante y, el acceso a los servicios sociales especializados es sólo un 'privilegio' de los migrantes residentes.

En términos generales el acceso a los servicios sociales está supeditado al registro en el padrón municipal de habitantes. Este último hecho ha sido motivo de amplio debate en la STC 17/2013, de 31 de enero. La Sentencia en cuestión es fruto del recurso de inconstitucionalidad 1024-2004 interpuesto por el Parlamento Vasco respeto a diversos preceptos de la Ley Orgánica 14/2003, de 20 de noviembre, entre otras normativas.

Entre otras decisiones la Sentencia en cuestión declara inconstitucional el art. 58.6 de la LOEx ya que no respetaba lo establecido en el art. 24 CE sobre la protección judicial de los derechos.

Nos interesa sin embargo centrarnos en un hecho que creemos está vinculado con el tema de este manuscrito relacionado con el acceso a datos del padrón municipal por la Policía Nacional. Según la sentencia en cuestión no existe vulneración ninguna ni de la Ley de Protección de Datos (LOPD) ni de la intimidad de los extranjeros, ya que los artículos $10.1 \mathrm{y}$ 13.1 CE lo facultan a fin de cumplir con los preceptos de la lucha contra la inmigración irregular. En concreto establece que las prácticas de control tampoco pueden considerarse discriminatorias hacia los extranjeros ya que “...se dirige a controlar la regularidad y permanencia de los extranjeros en España en los términos dispuestos por el legislador orgánico, el cual puede perseguir lícitamente dicha finalidad garantizando así el respeto a la ley evitando su vulneración" (ROJO, 2013). 
Sin embargo, tanto expertos en extranjería como el voto particular, consideran que se vulnera de forma indirecta los derechos de educación y asistencia sanitaria ya que su ejercicio depende del empadronamiento (AJA, 2013) y, el honor y la intimidad personal y familiar de los extranjeros, establecido en el art. 18.4 CE (ROJO, op. cit.).

El voto particular en concreto considera, entre otras cuestiones, que el padrón municipal es básicamente un registro administrativo que se constituye en condiciones para el ejercicio de derechos y no un instrumento de control de flujos (ibídem).

Más allá de la Ley de Extranjería española, otros instrumentos que discriminan entre la regularidad e irregularidad administrativa en el ejercicio de los derechos son el Real Decreto 16/2012, de 20 de abril y la Ley Orgánica 4/2015, de 30 de marzo, de protección de la seguridad ciudadana. La primera prestablece que la asistencia sanitaria se restringe a los residentes trabajadores y sus beneficiarios salvo casos de excepción y de necesidad urgente y, la segunda, vulnerando varios compromisos internacionales, la Constitución española y la propia LOEx, planteando la "devolución en caliente" de los migrantes en situación de irregularidad administrativa. No desarrollaremos su contenido en este manuscrito da su extenso debate.

No solamente en el marco español se discrimina entre extranjeros residentes irregulares, en el marco brasileño también existe una realidad similar. Por falta de jurisprudencia y datos bibliográficos sobre la materia en Brasil, así como que no se trata del tema central del presente trabajo, intentaremos introducir brevemente nociones sobre la cuestión del ejercicio de los derechos humanos por parte del migrante y su condición sociojurídica.

En la Constitución Federal Brasileña (CFB) se establece en el art. $5^{\circ}$ lo siguiente:

Todos son iguales ante la ley, sin distinción de cualquier naturaleza, garantizando así a los brasileños y a los extranjeros residentes en el país la inviolabilidad del derecho a la vida, a la libertad, a la igualdad, a la seguridad y a la propiedad...

Lo primero que es evidente en el contenido del artículo constitucional es la igualdad de los extranjeros frente a los brasileños, lo que normalmente es reclamado por los defensores de los derechos humanos en Brasil. Pero si lo analizamos y miramos fijamente, vemos que se refiere a extranjeros residentes. Por extranjeros residentes no se refiere a los todos los extranjeros residentes en el territorio brasileño sin excepción, sino aquellos que tienen 
autorización de residencia o se encuentra en el territorio en régimen de estancia o investigación. Por ello, el contenido del art. $5^{\circ}$ es a priori excluyente.

En este sentido, el ejercicio de ciertos derechos por parte de los extranjeros dependerá pues de su condición jurídica de regular o irregular en el territorio brasileño.

En esta línea de reflexión, Garcia Medina expone en su trabajo que a pesar que se deba reconocer que el núcleo esencial de los derechos asegurados a los extranjeros incluye "las prerrogativas necesarias al amparo de la dignidad humana (STF, AgRg en RE 346.180, rel. Min. Joaquim Barbosa, 2a T., j. 14.06.2011), la conformación de los derechos fundamentales, de todos modos, depende de lo establecido en los párrafos del art. 5 (GARCIA MEDINA, 2014: 61).

Tan solo en el art. $3^{\circ}$, párrafo IV del Código Civil Federal (CVF) no se discrimina por nacionalidad a los extranjeros. En el artículo en cuestión se dispone que uno de los objetivos fundamentales de la República Federativa de Brasil es promover el bien de todos, sin prejuicio de origen, raza, sexo, color, edad o cualquier otra forma de discriminación. El contenido del art. $3^{\circ} \mathrm{CVF}$ genera, al menos, una duda, teniendo en cuenta que la Constitución es la norma superior y discrimina entre extranjeros residentes y no residentes, ¿debemos, pues, tener en cuenta, en este caso, el principio del trato favorable y el principio favor personae?

Además de la discriminación entre extranjeros regulares o irregulares dispuesto en la Constitución federal, y a pesar de que se prohíba la discriminación entre brasileños y extranjeros, algunos derechos son restringidos a las personas migrantes en Brasil. Así, sólo por citar algunos ejemplos, el derecho de extradición, derechos políticos y públicos y las acciones populares, son permitidos a los brasileños y restringidos a los extranjeros en Brasil.

En definitiva, a diferencia del principio universal a priori que reconoce derechos a todos y todas sin excepción, su contextualización, en este caso en la LOEx y respeto a los derechos sociales y colectivos en España, así como en relación a los derechos de los extranjeros en Brasil quedan restringidos, por lo menos, por la condición sociojurídica del migrante. 


\section{Conclusiones}

A modo de conclusión, consideramos atrevido situar a la misma altura, aunque sea desde el punto de vista complementario, la condición sociojurídica como un factor de garantía de derechos a nivel de aquellos planteados por juristas de renombre y amplio reconocimiento. Sin embargo, creemos que es necesario no porque no se haya planteado antes sino para que se convierta en uno de los elementos principales en el que fijarnos a la hora de referirnos a la efectividad de los derechos de los migrantes.

En esta línea somos conscientes que ello requiere no solo voluntad personal y profesional, sino igualmente cambios de paradigma que nos conlleve a renombrar las cosas y reinventar los conceptos según las necesidades temporales y espaciales $\mathrm{y}$, haciendo justicia a la memoria histórica. En lo referente al presente manuscrito se hace necesario adaptar los conceptos de Estado, derechos humanos y migrante a la condición social de aquél y aquella que en condiciones de debilidad se desplaza de un lugar a otro, es decir, del migrante.

Igualmente se hace necesario una visión que supere las dicotomías y los simplismos de los hechos y que intente percibir la realidad social desde la transdisciplinaridad, los procesos de relaciones sociales, políticas, teóricas, productivas, culturales, económicas e identitarias, y los aspectos complejos de las vidas de los sujetos, en este caso de los/las migrantes.

En este sentido los derechos humanos de los migrantes deben dejar de ser simple connotaciones inherentes a su condición humana para ser condiciones materiales e inmateriales reales, justas y sin desigualdades apriorísticas.

Creemos, pues, que debemos ser conscientes que no existe un "colectivo inmigrante" sino como mucho grupos, poblacionales migrantes y, por ello, las planificaciones de las políticas en la materia no pueden ser bajo el precepto de "todo vale igual" sino teniendo en cuenta la ambigüedad y complejidad de los migrantes.

Contextualizando la migración extranjera en España, creemos que es un desafío para las instituciones gubernamentales y la propia sociedad española, la llegada de individuos y grupos poblacionales procedentes de otras partes del mundo. Pero el "enfrentamiento" a este desafío debe hacerse desde un enfoque más solidario, abierto, humanista y asumir que la heterogeneidad es una de las señas de identidad de la sociedad española desde hace siglos y, en particular de la sociedad andaluza. En Brasil, la realidad migratoria forma parte de su ADN ya que la constitución y construcción de la sociedad se dio a través de varios procesos migratorios. 
Hablar de la relación entre el acceso y/o disfrute de los derechos humanos y la condición sociojurídica de los migrantes significa, en parte, plantear el debate en torno a la ciudadanía. Ésta última desde la época decimonónica sigue vinculada a la nacionalidad obligando a naturalizarse a todos aquellos y aquellas que quieran formar parte de la 'citizenship'. Así pues, a priori, el vínculo con un territorio determinado es supuestamente una condición sine qua non para el acceso a la membresía y pertenencia a una nación.

Dicha obligación de naturalización forma parte de un proceso de construcción identitaria homogénea y la reafirmación de extraños y ajenos a esta homogeneidad que en el caso de España es necesario echar la vista atrás y recuperar varios escenarios históricos que muestran aportaciones sociales y culturales y presencias de aquellos hoy considerados ajenos a lo cultural e identitario español. En el caso brasileño la esquizofrenia de la mayoría social, la gestión del mestizaje y las características de las políticas migratorias actuales hace que se perciba al migrante como extraños y ajenos al supuesto marco nacional homogéneo.

En esta línea de debate en torno a la ciudadanía dada además las características de las políticas migratorias europeas y españolas, a los migrantes se les reconocerá una ciudadanía material relacionada con su condición de trabajador o trabajadora. Se dará así pues una cierta estratificación cívica dependiendo de la condición jurídica que tienen los migrantes. Pero es cierto que dicha estratificación es sólo formal ya que el citizens, denizens o inmigrantes con autorización de residencia temporal pueden tener reconocidos formalmente ciertos derechos en tanto ciudadanos, pero si no logran cumplir o mantener con las claves preestablecidas por la centralidad del trabajo, pueden pasar de un día al otro al lado de los incluidos de forma diferencial, que sería lo mismo que excluidos.

En base a lo expuesto los migrantes temporales en España no solamente quedarán exentos de la condición de ciudadanía por los desajustes económicos y financieros al tratarse de grupos sociales con amplias desigualdades económicas y sociales, sino que además no están apriorísticamente en el listado histórico de Españoles ya que han sido previamente concebidos, por lo histórico y lo social, como ajenos y extraños a la cultura Española.

Frente a ello es necesario por un lado cambios de paradigmas en torno al fenómeno migratorio y, reflexiones profundas sobre la determinación apriorística de la ciudadanía, construcción de extraños y ajenos a un aspecto cultural homogéneo, así como un concepto de ciudadanía más acorde con las características culturales e identitarias de la sociedad española actual. 
Tal como dijimos al inicio de estas conclusiones en el proceso de acceso y disfrute de los derechos por parte de los migrantes es importante tener en cuenta la condición sociojurídica como uno de los factores de facilidad u obstaculización. La determinación de la condición sociojurídica se enmarca en la línea de las prerrogativas estatales y legisladoras, algo amparado tanto por la CE como por la LOEx, pero que sin embargo carece que, de ciertos principios morales, solidarios, de cooperación internacional, cooperación al desarrollo, codesarrollo y hasta de percepción de involución de las sociedades europea y española en principios sociales y democráticos. Es decir, se percibe que los tratos a los migrantes en Europa y en España como algo ajeno al tratarse de una 'relación' con alguien extraño a lo europeo y español.

En este vínculo entre el acceso y disfrute de derechos y la condición sociojurídica se restringe el acceso a derechos como de sindicación y huelga, participación política, ayudas en materia de vivienda, educación, reagrupación familiar, derechos sociales, intimidad personal y familiar, asistencia sanitaria, entre otros. En el caso brasileño no solamente se discrimina entre migrante regular e irregular, sino que además se discrimina el acceso y disfrute de ciertos derechos dependiendo de la pertenencia o no al territorio, es decir, nacional o extranjero.

Incluir la condición sociojurídica en el juego de acceso y disfrute de derechos por parte de los migrantes nos permite percatar que a diferencia del principio universal a priori que reconoce derechos a todos y todas sin excepción, su contextualización, en este caso en la LOEx y respeto a los derechos sociales y colectivos en España, así como de los extranjeros en Brasil, quedan restringidos, por lo menos, por la condición sociojurídica del migrante y a su nacionalidad.

Ante eso es necesario y urgente iniciar una reflexión que permita que prevalezca la condición de Ser Humano del migrante, de individuo cultural, la convivencia familiar, sus necesidades y demandas sociales, así como su arraigo en el contexto donde resida o conviva.

\section{Referências}

ABRAMOVICH, V; COURTIS, C. Hacia la exigibilidad de los derechos económicos, sociales y culturales. Estándares internacionales y criterios de aplicabilidad antes los tribunales locales. In: ABREGÚ, M. y COURTIS, C. La aplicación de los tratados internacionales sobre derechos humanos por los tribunales locales. Argentina: Del Puerto/CELS. 1997, p. 283-350. 
. Los derechos sociales como derechos exigibles. Madrid: Trotta, 2002.

AGUIAR DE LUQUE, L. Las garantías constitucionales de los derechos fundamentales en la Constitución Española. Madrid: UNED, Facultad de Derecho, 1981.

AJA, E. Los derechos de los extranjeros: calidad de la ley y de las sentencias. Barcelona: Institut de Dret Públic, 2013. Disponivel em: $<$ http://idpbarcelona.blogspot.com.es/2013/03/los-derechos-de-los-extranjeros-calidad.html $>$. Acesso em: 12/04/2015)

ALBA MONTESERIN, S; FERNÁNDEZ ASPERILLA, A; MARTÍNEZ VEGA, U. Crisis económica y el nuevo panorama migratorio en España. Madrid: Fundación $1^{\circ}$ de mayo, 2013.

ANDERSON, B. Comunidades imaginadas. Reflexiones sobre el origen y la difusión del nacionalismo. México: ed. Efe. Fondo de Cultura Económica, 2000.

ARANGO, J. Derechos sociales, ciudadanía e integración. Inmigración y derechos de ciudadanía. Barcelona: CIDOB, 2006. p. 118-125.

ARENDT, H. La condición humana. Traductor: Ramón Gil Novales. Argentina: Paidós, 2003.

BHABBA, H. The location of culture. London and New York: Routledge, 1994.

BOBBIO, N. El tiempo de los derechos. trad. Rafael de Asís, Madrid: Sistema. Fundación Sistema, 1991.

CARENS, J. The ethics of immigration. Oxford: Oxford University Press, 2013.

CHACÓN RODRÍGUEZ, L. De suecas a ecuatorianas y el retorno de la política. Inmigración y derechos de ciudadanía. Barcelona: CIDOB, 2006. p. 46-65.

DE LUCAS, J.; AÑON ROIG, M.J. Sobre resistencia, ciudadanía y democracia. Revista El Cronista social del Estado social y democrático de Derecho. n. 32. p. 18-24, 2012.

. La inmigración como res política. In: CHAMIZO DE LA RUBIA, J.; YAMGNANE, $\mathrm{K}$. (eds.) Movimientos de personas e ideas y multiculturalidad. Deusto: ed. Universidad de Deusto, 2003.

. Hacia una ciudadanía europea inclusiva. Su extensión a los inmigrantes. Revista Cidob

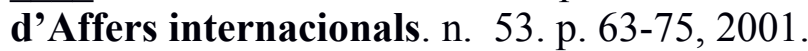

FERRAJOLI, L. Derecho y razón. Teoría del garantismo penal. Madrid: Trotta, 1995.

. Derechos y garantías. La ley del más débil. Madrid: Trotta, 2004.

. Poderes salvajes. La crisis de la democracia constitucional. Madrid: Trotta, 2011.

Guaju, Matinhos, v.1, n.2, p. 23-40, jul./dez. 2015 
GARCIA MEDINA, J. M. Constituição Federal: comentada. 3. ed. Brasilia: Revista dos Tribunais, 2014

HERRERA FLORES, J. Los derechos humanos como productos culturales. Crítica del humanismo abstracto. Madrid: Los libros de Catarata, 2005.

- La Reinvención de los derechos humanos. Sevilla: ed. Atrapasueños/ Colección Ensayando, 2008.

MARTIN, E. La inmigración andaluza a Cataluña: causas, sistemas de organización y trasplante de la cultura andaluza. In: PRATS, J.; CONTRERAS, J; MARTÍNEZ, U; MORENO, I. (eds.) Antropologías de los pueblos de España. Madrid: Taurus, 1991. p. 299306.

MEZZADRA, S. La condizione postcoloniale. Storia e política nel mondo globale. Bologna: Ombre Corte, 2008.

.Oltre la cittadinanza. La politica dei governati. Partha Chatterjee. (Traduzione Matteo Bortolini), Roma: ed. Meltemi, 2006.

- Derecho de fuga. migraciones, ciudadanía y globalización. Madrid: Tinta limón ediciones/ Mapas. Traficantes de sueños, 2005.

The Gaze of Autonomy. Capitalism, Migration, and Social Struggles. In: V. SQUIRE (ed), The Contested Politics of Mobility: Borderzones and Irregularity. London: Routledge, 2011.

MIGNOLO, W. Historias locales/diseños globales. Colonialidad, conocimientos subalternos y pensamientos fronterizos. Madrid: Akal, 2003.

MORIN, E. Introducción al pensamiento complejo. Barcelona: Gedisa, 1994.

MORRIS, L. Managing migration: civic stratification and migrant's rights. London: Routledge, 2002.

MOYA, D.; AGUELO NAVARRO, P. La reforma de la Ley Orgánica de Extranjería. Madrid: ed. Centro de Estudios Políticos y Constitucionales, 2011.

PECES-BARBA MARTÍNEZ, G. Derechos fundamentales. Madrid: Latina Universitaria, 1980.

PISARELLO, G. Los derechos sociales y sus garantías. Madrid: Trotta, 2007.

ROJO TORRECILLA, E. ¿Volvemos al debate entre control de la inmigración y políticas de integración, entre seguridad y libertad? Un apunte a propósito de la Sentencia del Tribunal Constitucional sobre la LO 14/2003. 2013. El blog de Eduardo Rojo. Disponível em: $<$ http://www.eduardorojotorrecilla.es/2013/02/volvemos-al-debate-entre-control-de-la.html $>$. Acesso em: 12/04/2015. 
SOLANES CORELLA, A. Sujetos al margen de ordenamiento jurídico: inmigrantes sin papeles. In: DE LUCAS, J; PEÑA, S.; SOLANES, A. Trabajadores migrantes. Valencia: Germania, 2001. p. 201-218.

SOLANES CORELLA, A. Un balance tras 25 años de leyes de extranjería en España. Revista del Ministerio de Trabajo e Inmigración. n. 90. p. 77-102, 2010.

TOMÉ DA MATA, E. La efectividad de los derechos sociolaborales de los inmigrantes negroafricanos en Andalucía. Tese (doutorado Facultad de Ciencias Sociales)Departamento de Trabajo Social y Servicios Sociales, Universidad Pablo de Olavide, 2011.

TREVES, R. Derecho y cultura. Buenos Aires: Editorial DEPALMA, 1947.

VIRUELA, R. La nueva corriente migratoria de Europa del Este. Cuadernos de geografía. $\mathrm{n}$. 72. p. 231-258, 2002.

VIRUELA, R. Movilidad geográfica de los rumanos. Estructura territorial de las migraciones interiores en España. EMPIRIA. Revista de Metodología de Ciencias Sociales. n. 19. p. 157$181,2010$.

VV.AA. Los derechos de participación como elemento de integración de los inmigrantes. Bilbao: ed. Fundación BBVA, 2008.

ZINCONE, G.; PENNINX, R.; BROKERT, M. (eds.). Migration Policymaking in Europe: the Dynamics of Actors and Contexts in Past and Present. Amsterdam: Amsterdam University Press, 2011.

. Da sudditi a cittadini. Le vie dello Stato e le vie della società civile. Bologna: Ed. Il Mulino, 1992.

Artigo recebido em 08/12/2015. Aceito para publicação em 15/01/2016. 